\title{
Impact of Terms-of-Trade on Business Cycles of Slovakia, Czech Republic and Croatia
}

\author{
Karol Szomolányi \\ University of Economics Bratislava, Slovakia \\ Martin Lukáčik \\ University of Economics Bratislava, Slovakia \\ Adriana Lukáčiková \\ University of Economics Bratislava, Slovakia
}

\begin{abstract}
Different theoretical and empirical studies lead to the different results. Different theories suggest a positive as well as a negative relation between the terms-of-trade and trade balance. The traditional Keynesian Harberger-Laursen-Metzler effect of the terms-of-trade on the trade balance is positive. According to the ObsfeldSvensson-Razin effect the positive relation between the terms-of-trade and trade balance is the smaller, the higher a persistence of the terms-of-trade shocks is. The empirical studies do not support statistically significant impact of the terms-of-trade on the output in the developing countries. The goal of the paper is to verify an impact of the terms-of-trade on the Slovak Czech and Croatian business cycles and trade balances. Using the structural vector auto-regression analysis of the terms-oftrade, trade balance, output, consumption and investment cyclical components, we show that the relationship between the terms-of-trade and trade-balance is negative in the Slovak and Czech economy. The relationship between the terms-oftrade and trade-balance is statistically insignificant in the Croatian economy. Termsof-trade shocks explain only small fraction of business cycles in the Slovak, Czech and Croatian economies. Data exhibit Obstfeld-Svensson-Razin effect of the termsof-trade on the trade balance.
\end{abstract}

Keywords: innovation, terms-of-trade, business cycle, Slovak economy, Czech economy, Croatian economy, trade balance, market

JEL classification: C32, E32, F14

Acknowledgments: This paper is supported by the Grant Agency of Slovak Republic VEGA, grant no. 1/0444/15 "Econometric Analysis of Production Possibilities of the Economy and the Labor Market in Slovakia".

\section{Introduction}

The terms-of-trade is theoretically significant source of business cycles and it causes shifts in the trade balance. However different theoretical and empirical studies lead to the different results of the short-run terms-of-trade impact on the output and on the trade balance. There are two theoretical effects of terms-of-trade impact on trade balance. Harberger (1950) and Laursenet al (1950) used traditional Keynesian model to show that the trade balance grows with the terms-of-trade. On the contrary, the dynamic optimizing models of Obstfeld (1982) and Svenssonet al (1983) 
leads to a conclusion that the positive effect of terms-of-trade on the trade balance is the smaller the more persistent a terms-of-trade shock is. Using a small open economy real business cycle model (or a dynamic stochastic general equilibrium model) Uribe et al (2016) showed that by capital adjustment costs the theoretical effect may be even negative. The empirical studies of Aguirre (2011), Broda (2004) and Uribe et al (2016) surprisingly do not support a statistically significant impact of the term-of-trade on the output in poor and emerging countries. In general authors can confirm an intuition that the more open the economy is the higher effect of terms-on-trade on trade balance is. This result may be theoretically achieved by using theoretical general equilibrium models only if non-tradable goods are considered. Uribe et al (2016) developed models with tradable and non-tradable goods to show that an existence of non-tradable goods "reduce the importance of terms-of-trade shocks".

The goal of the paper is to verify an impact of terms-of-trade on the Slovak, Czech and Croatian business cycles and on the trade balance. The brief economic review is presented in the introduction. We provide an empirical measure based on structural vector auto-regression (SVAR) econometric specification similar to one presented by Uribe et al (2016). This methodology is described in the following section. We use Slovak and Czech quarterly data in the period 1997 to 2014 and Croatian quarterly data in the period 2000 to 2014 . We compute the responses on terms-of-trade impulse and variance decompositions of terms-of-trade shocks displayed in the results section. We will show that a terms-of-trade shock leads to the immediate decrease in trade balance and has no impact on aggregate output in the analyzed countries. Corresponding interpretations are discussed in the last section.

\section{Methodology}

We used vector autoregressive (VAR) models for our analysis. It is well known that in VAR models every endogenous variable is a function of all lagged endogenous variables in the system. See Lütkepohl (2005) for more details about VAR models. The mathematical representation of the unrestricted VAR model of order $p$ is:

$$
\mathbf{y}_{\mathrm{t}}=\mathbf{A}_{1} \mathbf{y}_{\mathrm{t}-1}+\mathbf{A}_{2} \mathbf{y}_{\mathrm{t}-2}+\ldots+\mathbf{A}_{\mathrm{p}} \mathbf{y}_{\mathrm{t}-\mathrm{p}}+\mathbf{e}_{\mathrm{t}}
$$

Where $\mathbf{y}_{\mathbf{t}}$ is a $k$ vector of endogenous variables; $\mathbf{A}_{\mathbf{1}}, \mathbf{A}_{\mathbf{2}}, \ldots, \mathbf{A}_{\mathbf{p}}$ are matrices of coefficients to be estimated; and $\mathbf{e}_{\boldsymbol{t}}$ is a vector of innovations that may be contemporaneously correlated but are uncorrelated with their own lagged values.

The VAR model (1) can be interpreted as a reduced form model. A structural vector autoregressive (SVAR) model is defined as:

$$
A \mathbf{y}_{\mathbf{t}}=\mathbf{B}_{1} \mathbf{y}_{\mathrm{t}-1}+\mathbf{B}_{2} \mathbf{y}_{\mathrm{t}-2}+\ldots+\mathbf{B}_{\mathrm{p}} \mathbf{y}_{\mathrm{t}-\mathrm{p}}+\mathbf{B} \mathbf{u}_{\mathrm{t}}
$$

It is assumed that the structural errors, $\mathbf{u}_{\boldsymbol{t}}$ are white noise and the coefficient matrices $\mathbf{B}_{1}, \mathbf{B}_{2}, \ldots, \mathbf{B}_{\mathbf{p}}$ are structural coefficients that in general differ from their reduced form counterparts and $\mathbf{B}$ is matrix of restrictions on $\mathbf{U}_{\mathbf{t}}$.

A SVAR model can be used to identify shocks and trace these out by employing impulse response analysis and variance decomposition through imposing restrictions on used matrices. Uribe et al (2016) proposed a specification of the SVAR, through which we can determine responses on terms-of-trade impulse: 


$$
\mathbf{A}\left(\begin{array}{c}
t o t_{t} \\
t b_{t} \\
y_{t} \\
c_{t} \\
i_{t}
\end{array}\right)=\mathbf{B}_{1}\left(\begin{array}{c}
t o t_{t-1} \\
t b_{t-1} \\
y_{t-1} \\
c_{t-1} \\
i_{t-1}
\end{array}\right)+\mathbf{B}\left(\begin{array}{c}
u_{t}^{t o t} \\
u_{t}^{t b} \\
u_{t}^{y} \\
u_{t}^{c} \\
u_{t}^{i}
\end{array}\right)
$$

where tot is relative cyclical component of the terms of trade, th is relative cyclical component of the trade balance to output ratio, $y$ is relative cyclical component of output, $c$ is relative cyclical component of consumption, $i$ is relative cyclical component of investment.

The $U_{t}^{t o t}, U_{t}^{t+b}, U_{t}{ }^{\dagger}, U_{t} c$ and $U_{t}^{i}$ are structural shocks of given variables. We estimated the parameters of the SVAR specification (3) using the Amisano et al (1997) approach. The class of commonly used models may be written as:

$$
\mathbf{A e}_{\mathbf{t}}=\mathbf{B u}_{\mathbf{t}}
$$

The structural innovations $\mathbf{u}_{\boldsymbol{t}}$ are assumed to be orthonormal, i.e. its covariance matrix is an identity matrix $\boldsymbol{\Sigma}_{\mathbf{u}}=\mathbf{I}$. The assumption of orthonormal innovations imposes the following identifying restrictions on $\mathbf{A}$ and $\mathbf{B}$ :

$$
\mathbf{A} \boldsymbol{\Sigma}_{\mathbf{e}} \mathbf{A}^{\mathbf{T}}=\mathbf{B B} \mathbf{B}^{\mathbf{T}}
$$

Noting that the expressions on both sides of (5) are symmetric, this imposes $k(k+1) / 2=15$ restrictions on the $2 k^{2}=50$ unknown elements in $\mathbf{A}$ and $\mathbf{B}$. Therefore, in order to identify $\mathbf{A}$ and $\mathbf{B}$, we need to impose $\left(3 k^{2}-k\right) / 2=35$ additional restrictions. The matrix $\mathbf{A}$ of unrestricted specification is a lower triangular matrix with unit diagonal ( 10 zero and 5 unity restrictions) and matrix $\mathbf{B}$ is a diagonal matrix (20 zero restrictions) in this just-identified specification. Other tested restrictions are imposed on elements of $\mathbf{A}$ (matrix of contemporary effects between endogenous variables), which means that our specification becomes over-identified and also testable.

We verified the stability of a VAR model (i.e. whether all roots have modulus less than one and lie inside the unit circle). We estimated the parameters of restricted and unrestricted specifications. Using the logarithm of the maximum likelihood functions of both specifications we calculated the likelihood ratio statistics and verified the significance of restrictions. All tests are explained in Lütkepohl (2005).

Using matrix polynomial in lag operator $\mathbf{A}(L)=\mathbf{B}_{1} L+\mathbf{B}_{2} L^{2}+\ldots+\mathbf{B}_{p} L^{p}$ we can rewrite (2) as SMA representation:

$$
\mathbf{y}_{\mathbf{t}}=[\mathbf{A}-\mathbf{A}(L)]^{-1} \mathbf{B} \mathbf{u}_{\mathbf{t}}=\mathbf{C}(L) \mathbf{u}_{\mathbf{t}}=\mathbf{C}(0) \mathbf{u}_{\mathbf{t}}+\mathbf{C}(1) \mathbf{u}_{\mathbf{t}-\mathbf{1}}+\mathbf{C}(2) \mathbf{u}_{\mathbf{t}-2}+\ldots+\mathbf{C}(h) \mathbf{u}_{\mathbf{t}-\mathbf{h}}+\ldots
$$

Hence, $\mathbf{C}(0)$ is the coefficient matrix on impact, $\mathbf{C}(1)$ at a one period lag, $\mathbf{C}(2)$ at a two period lag, and so on. Generally, $\mathbf{c}_{i, j}(h)$ element is the impulse response of variable $i$ to shock $j$ at horizon $h$. The forecast error of $\mathbf{y}$ at horizon $s$ is:

$$
\mathbf{y}_{\mathbf{t}+\mathbf{h}}-\hat{\mathbf{y}}_{\mathbf{t}+\mathbf{h}}=\mathbf{C}(0) \mathbf{u}_{\mathbf{t}+\mathbf{h}}+\mathbf{C}(1) \mathbf{u}_{\mathbf{t}+\mathrm{h}-\mathbf{1}}+\mathbf{C}(2) \mathbf{u}_{\mathbf{t}+\mathrm{h}-\mathbf{2}}+\ldots+\mathbf{C}(h) \mathbf{u}_{\mathbf{t}}
$$

Variance of the forecast error (assuming orthogonality) is expressed as sum of the individual variances of shocks:

$$
\operatorname{var}\left(\mathbf{y}_{\mathbf{t}+\mathbf{h}}-\hat{\mathbf{y}}_{\mathbf{t}+\mathbf{h}}\right)=\mathbf{C}(0) \mathbf{I C}(0)^{\mathbf{T}}+\mathbf{C}(1) \mathbf{I C}(1)^{\mathbf{T}}+\mathbf{C}(2) \mathbf{I C}(2)^{\mathbf{T}}+\ldots+\mathbf{C}(h) \mathbf{I C}(h)^{\mathbf{T}}
$$

The fraction of the forecast error variance of variable $i$ due to shock $j$ at horizon $h$, is then the $(i, j)$ element of expression (8) divided by the total forecast error variance and is expressed as a percentage. We calculated the impulse response functions (IRF) and realized variance decomposition (VD) to quantify the short-term impact of shocks. Generally, the IRF traces the effect of a one-time shock in one of the innovations on current and future values of the endogenous variables and VD is a way to quantify how important each shock is in explaining the variation of each of the variables in the system. 


\section{Results}

\section{Slovakia}

The responses to the terms-of-trade shock are in the Figure 1. As the output shock elasticity coefficient is not statistically significant $(0$ is in the two standard deviation interval), the improvement in terms-of-trade has no impact on the aggregate activity and the one-quarter delayed output expansion is statistically insignificant. Investment displays a somewhat larger expansion, albeit with a one-quarter delay. Consumption expansion is slightly over the limit of statistical significance. The $10 \%$ increase in the terms-of-trade causes an increase of $1.5 \%$ in consumption. On the other hand, the impact of the terms-of-trade shock on trade balance is statistically significant. The $10 \%$ increase in the terms of trade causes a decrease of $7.2 \%$ in trade balance. Furthermore a huger contraction is delayed by one quarter. The result suggests confirmation of Obstfeld-Svensson-Razin effect.

Figure 1

Impulse Response Functions to Terms-of-Trade Shock in Slovakia
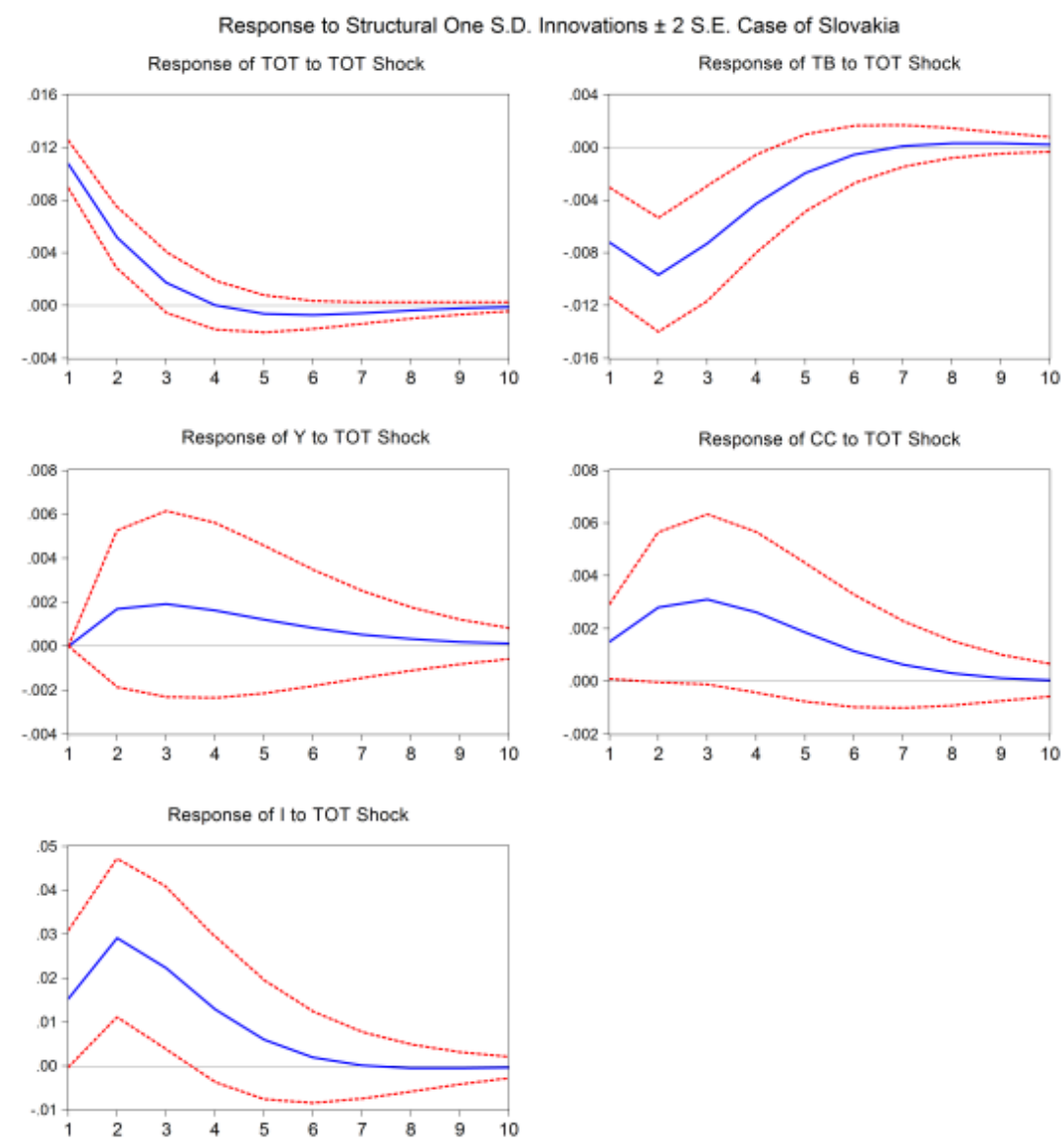

Source: Author's illustration

To gauge the importance of the terms-of-trade shock we compute the fraction of the variance of all indicators of interest explained by terms-of-trade, i.e. we compute the variance decomposition. The share of variance explained by terms-of-trade shocks in Slovakia are $100 \%$ for variance of terms-of-trade, $15.7 \%$ for variance of trade balance, $0 \%$ for variance of output, $1.2 \%$ for variance of consumption and $3.1 \%$ for variance of investment. 


\section{Czech Republic}

The responses to the terms-of-trade shock are in the Figure 2. As output shock elasticity coefficient is not statistically significant, the improvement in terms-of-trade has no impact on the aggregate activity and the one-quarter delayed output expansion is statistically insignificant. Consumption exhibits the same insignificant results as output. Investment expansion is slightly over the limit of statistical significance. The $10 \%$ increase in the terms-of-trade causes an increase of $6.9 \%$ in investment. The $10 \%$ increase in the terms of trade causes a decrease of $2.1 \%$ in trade balance. As in the case of Slovakia, the result suggests confirmation of Obstfeld-Svensson-Razin effect of the terms-of-trade.

Figure 2

Impulse Response Functions to Terms-of-Trade Shock in Czech Republic
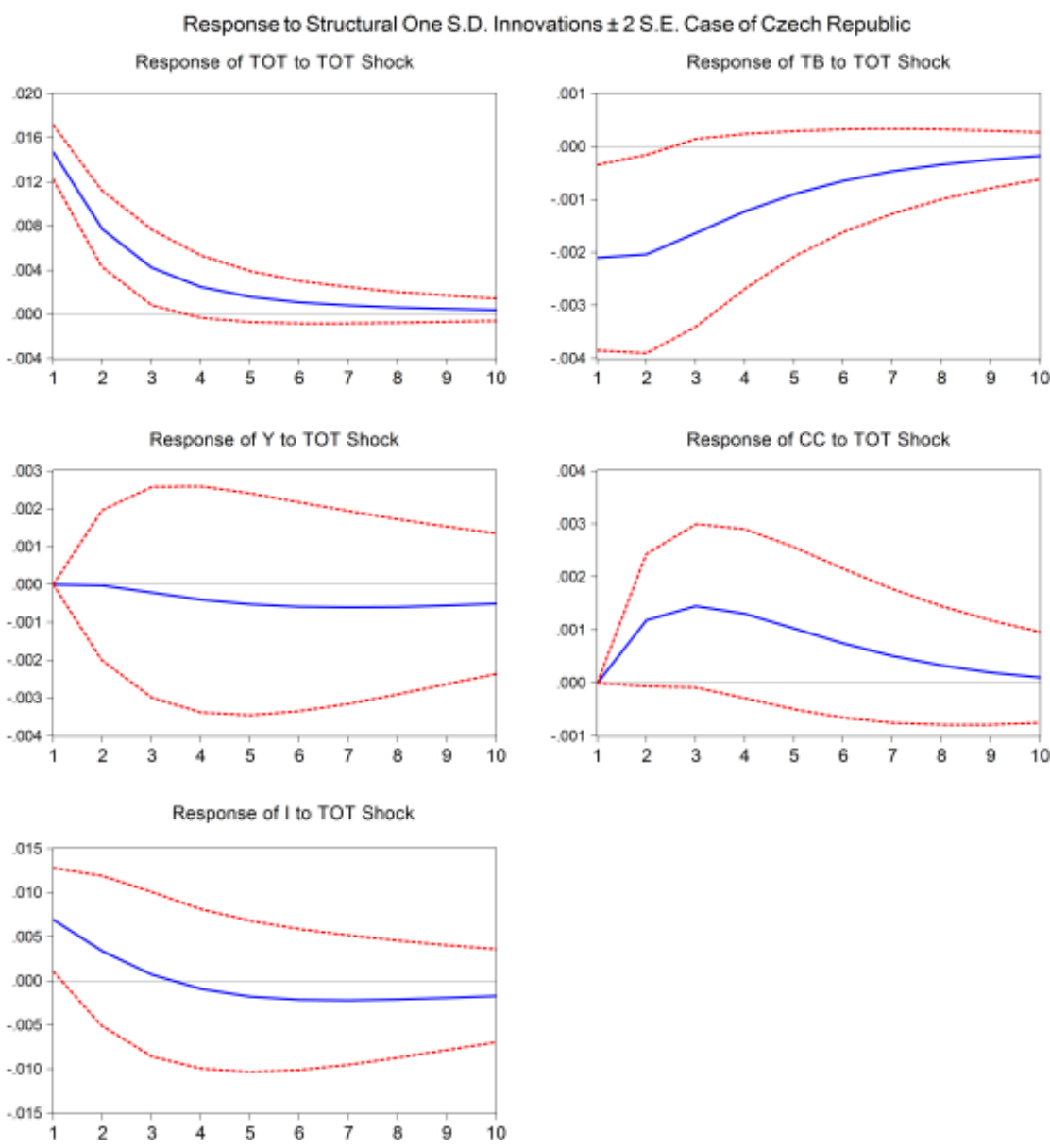

Source: Author's illustration

Share of variance explained by terms-of-trade shocks in Czech Republic are $100 \%$ for variance of terms-of-trade, $7.7 \%$ for variance of trade balance, $0 \%$ for variance of output, $0 \%$ for variance of consumption and $3.3 \%$ for variance of investment.

\section{Croatia}

The responses to the terms-of-trade shock are in the Figure 3. The improvement in terms-of-trade has no impact on the aggregate activity, consumption, investment 
and terms-of-trade. Nevertheless, as in case of Slovakia and Czech Republic, the result suggests confirmation of Obstfeld-Svensson-Razin effect of the terms-of-trade.

Figure 3

Impulse Response Functions to Terms-of-Trade Shock in Croatia
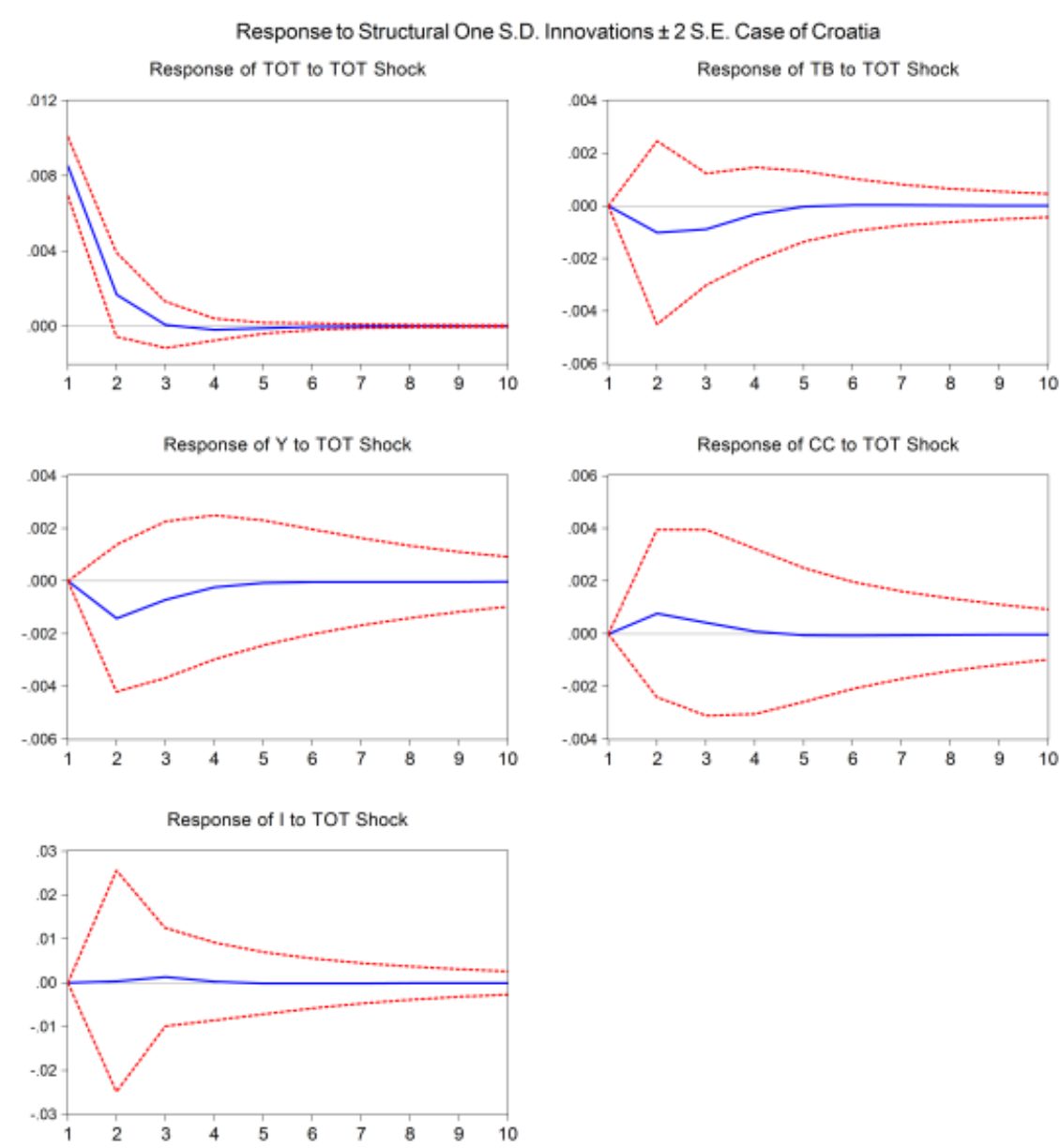

Source: Author's illustration

Share of variance explained by terms-of-trade shocks in Croatia are $100 \%$ for variance of terms-of-trade and0\% for variance of trade balance, output, consumption and investment.

\section{Discussion and Conclusion}

The terms-of-trade has significant impact on the trade balance in Slovakia and Czech Republic. We cannot confirm a statistically significant impact of the terms-oftrade on the trade balance in Croatia. These results support the Obstfeld-SvenssonRazin effect rather than the Harberger-Laursen-Metzler effect. As Uribe et al (2016) showed this correlation is in average positive in the developing countries over the world. From the theoretical background it follows that the negative or no effect of the terms-of-trade on the trade balance comes from persistent terms-of-trade shocks or from big capital costs.

However, Szomolányi et al (2013) showed that capital costs are not significant source of the Slovak and Czech business cycles. Using the SVAR analysis of the output, investment, trade balance, world interest rate and domestic interest rate 
they showed that more than $90 \%$ of business cycles is addressed to the output shocks. Therefore we suggest that terms-of-trade shocks are relatively highly persistent in these two countries. Main imported goods to the Slovakia and Czech Republic have been energy goods as natural gas and oil. On the other hand both countries have been exporting mainly cars. In fact prices of these goods are changing more permanently as usual.

Our result confirm the empirical evidence of Aguirre (2011), Broda (2004) and Uribe et al (2016) that terms-of-trade shocks explain a very little fraction of the output variance in emerging countries including Slovakia, Czech Republic or Croatia. This evidence can be theoretically explained by an existence of non-tradable goods. A challenge is to form and solve a theoretical model with non-tradable goods explaining acontribution of the trade balance on short-run macroeconomic performance.

A success of the SVAR models in explaining business cycles depends on a correct econometric specification which comes from a proper theoretical model. The specification used in the paper is helpful in understanding that the terms-of trade shocks do not drive the business cycles in the studied countries. A subject of authors' future research is to form a theoretical model suggesting an appropriate empirical model to find main sources of the business cycles in the post-communist countries.

\section{References}

1. Aguirre, E. (2011), Business Cycles in Emerging Markets and Implications for the Real Ex-change Rate, Ph.D. Dissertation, Columbia University, New York.

2. Amisano, G., Giannini, C. (1997), Topics in Structural VAR Econometrics, 2nd ed, Springer-Verlag, Berlin.

3. Broda, C. (2004), "Terms of Trade and Exchange Rate Regimes in Developing Countries", Journal of International Economics, Vol. 63, No. 1, pp. 31-58.

4. Harberger, A.C. (1950), "Currency Depreciation, Income, and the Balance of Trade", Journal of Political Economy, Vol. 58, No. 1, pp. 47-60.

5. Laursen, S., Metzler L.A. (1950), "Flexible Exchange Rates and the Theory of Employment", Review of Economics and Statistics, Vol. 32, No. 4, pp. 281-299.

6. Lütkepohl, H. (2005), New Introduction to Multiple Time Series Analysis, Springer, Berlin.

7. Svensson, L.E.O., Razin, A. (1983), "The Terms of Trade and the Current Account: The Harberger-Laursen-Metzler Effect", Journal of Political Economy, Vol. 91, No. 1, pp. 97125.

8. Szomolányi, K., Lukáčik, M., Lukáčiková, A. (2013),"Obmedzeniana svetových finančnýchtrhoch a slovenská ekonomika", in Kolektivautorů (Ed.), INPROFORUM 2013: sborník z mezinárodnívědecké konference, 7.-8.listopadu 2013, Jihočeskáuniverzita v Českých Budějovicích, Ekonomická fakulta,ČeskéBudějovice,pp. 295-299, available at http://ocs.ef.jcu.cz/index.php/inproforum/INP2013/paper/view/277 / (18 March 2016)

9. Uribe, M., Schmitt-Grohé, S. (2016), "Open Economy Macroeconomics", available at http://www.columbia.edu/ mu2166/book/ / (18 March 2016)

\section{About the authors}

Karol Szomolányi was born in Bojnice in the Slovak Republic (formerly Czechoslovakia) in 1976. He is an associated professor of operations research and econometrics at University of Economics in Bratislava, Faculty of Economic Informatics, Department of Operations Research and Econometrics. He is a member of the Slovak Society for Operations Research. He deals with the macroeconomic analysis and econometrics. His areas of interest are real business cycle models and 
dynamic stochastic macroeconomic models and their use for developing countries of Eastern Europe. The author can be contacted at karol.szomolanyi@euba.sk.

Martin Lukáčik was born in Žilina in the Slovak Republic (formerly Czechoslovakia) in 1974. He is an associated professor of operations research and econometrics at University of Economics in Bratislava, Faculty of Economic Informatics, Department of Operations Research and Econometrics. He is a president of the Slovak Society for Operations Research. He deals with the econometric methods in macroeconomic framework and time series econometrics. His areas of interest are VAR models used in macroeconomics and forecasting methods. The author can be contacted at martin.lukacik@euba.sk.

Adriana Lukáčiková was born in Gelnica in the Slovak Republic (formerly Czechoslovakia) in 1971. She is an assistant professor of operations research and econometrics at University of Economics in Bratislava, Faculty of Economic Informatics, Department of Operations Research and Econometrics. She is a member of the Slovak Society for Operations Research. She deals with the computable general equilibrium models and econometrics. Her area of interest is econometric modelling of national economy. The author can be contacted at adriana.lukacikova@euba.sk. 